infective particles or as extractable infective nucleic acid, is produced only in minimal amounts. There are certain resemblances to the so-called lysogenic state of phage in bacteria. Here D.N.A. of the bacterial virus (or phage) is integrated more or less stably with the bacterial D.N.A. and divides with it. Procedures such as irradiation, treatment with chemicals, or superinfection may disrupt this lysogenic state, and phage is then liberated. But though this biological model may advance our knowledge of viral infection, attempts to change the interaction between tumour virus and malignant cell in similar ways have so far been unsuccessful.

It seems now most probable that if some human neoplasms are caused by viruses then these will not be found in sufficient amounts in the cells of the tumour to be extractable in the usual ways. This may account for the many failures hitherto described. A. B. Sabin and M. A. Koch, ${ }^{14}$ in a study of hamster tumours produced by SV40 virus, have found a new procedure-induction by association-by which to persuade the tumour cells to yield evidence of their virus origin. These workers associated living tumour cells in vitro with cells susceptible to the virus. The tumour cells were not required to proliferate or even to survive. The susceptible indicator cells were a stable line of Cercopithecus monkey kidney cells, which are destroyed by SV40 virus. The indication, then, of virus induction was a cytopathic effect in the susceptible cells. P. H. Black ${ }^{15}$ and colleagues have confirmed this work. An analogous situation appears to obtain for rat sarcomas produced by the Prague ${ }^{16}$ or Schmidt-Ruppin ${ }^{17}$ strain of Rous sarcoma virus. Again, virus cannot be extracted from the tumour cells, but it may be "induced" by association of them with chick embryo cells in vitro ${ }^{16}$ or in ovo. ${ }^{17}$ Sabin and Koch believed that their data "provide a new approach to the search for etiologically significant, dormant viruses in human cancers."

The isolation of virus from human tumours recently reported by Negroni and Bell and their colleagues may be examples of "induction by association," but how can we be sure that the viruses induced are causally related to the tumours? Can other viruses carried by, but latent in, the tumour cells be induced in the same way? There are other questions, too, that require answers. What is the nature of the "information" that passes from the tumour cell to the indicator cell ? Is it, for example, incomplete, non-infectious virus that can only be completed in the susceptible cell ? What, if any, antigenic changes or "fingerprints" are

1 Negroni, G., Brit. med. F., 1964, 1, 927.

2 Inman, D. R., Woods, D. A., and Negroni, G., ibid., 1964, 1, 929.

s Bell, T. M., Massie, A., Ross, M. G. R., and Williams, M., ibid., 1964, $1,1212$.

- Sabin, A. B., and Koch, M. A., Proc. nat. Acad. Sci. (Wash.), 1963, 49, 304

s Melnick, J. L., Science, 1962, 135, 1128.

'Huebner, R. J., Rowe, W. P., and Lane, W. T., Proc. nat. Acad. Sci. (Wash), 1962, 48, 2051.

' Huebner, R. J., Rowe, W. P., Turner, H. C., and Lane, W. T., ibid., 1963, 50, 379 .

${ }^{8}$ Black, P. H., Rowe, W. P., Turner, H. C., and Huebner, R. J., ibid., 1963, 50, 1148 .

๑ Habel, K., Proc. Soc. exp. Biol. (N.Y.), 1961, 106, 722.

10 Sjogren, H. O., Hellström, I., and Klein, G., Cancer Res., 1961, 21, 329.

11 Koch, M. A., and Sabin, A. B., Proc. Soc. exp. Biol. (N.Y.), 1963, 113, 4

12 Sjogren, H. O., F. nat. Cancer Inst., 1964, 32, 361, 375, 645, 661.

13 Rogers, S., Nature (Lond.), 1959, 183, 1815.

14 Sabin, A. B., and Koch, M. A., Proc. nat. Acad. Sci. (Wash.), 1963, 50, 407.

${ }^{15}$ Black, P. H., Rowe, W. P., and Cooper, H. L., ibid., 1963, 50, 847.

${ }^{16}$ Simkovic, D., Valentova, N., and Thurzo, V., Folia biol. (Praha), 1962, 8, 221.

${ }^{17}$ Harris, R. J. C., in Viruses, Nucleic Acids and Cancer, ed. R. W. Cumley. Baltimore. 1963. left in tumour cells by passenger viruses? How do tumour viruses containing R.N.A. interact with the cell's D.N.A. ? Can an alteration in D.N.A. be detected after infection?

These are among the main problems exciting the attention of virologists at present. In short, what is the nature of the interaction of the virus with the cell ? If malignancy can be the result of one mode of interaction there may be many viruses capable of causing human tumours, and some of them may have well-known names.

\section{Treatment of Cystinuria}

The introduction of D-penicillamine ${ }^{12}$ for the treatment of cystinuria has made the early diagnosis of this disease important. It is a rare disease and is inherited as a recessive character. A defect in the transport of amino-acids in the proximal renal tubules allows an excessive amount of cystine to pass out in the urine as well as the amino-acids arginine, lysine, and ornithine. Because cystine is relatively insoluble, it tends to precipitate and form stones in the urinary tract.

A cystine stone, when pure, shows as a faint opacity on $x$-ray examination of the abdomen. To the eye it is creamy white, pale pink, or yellow in colour, turning green after exposure to air. But appearances both on inspection and by radiography are unreliable because it may be composed in part of other materials. Moreover the observer is unlikely to have had the experience of examining many cystine stones. It is therefore wise to submit renal stones to chemical analysis. As well as attempting to detect cystine crystals, which may occur in acid urine as hexagonal plates, tests may also be performed on the urine, the nitroprusside test or amino-acid chromatography being suitable.

D-Penicillamine is produced by the hydrolysis of penicillin. It is a sulphur-containing amino-acid $(\beta \beta$ dimethyl cysteine) with an asymmetric carbon atom, the $\mathbf{D}$ (dextro) form being used therapeutically. Because it is a chelating agent (being able to combine with copper and lead) it is used in the treatment of both Wilson's disease and lead poisoning. Recently it has also been advocated as a diagnostic aid when lead poisoning is suspected, ${ }^{3}$ for it can cause a measurable increase in the excretion of the metal. In the treatment of cystinuria D-penicillamine forms a soluble mixed disulphide with cystine, and this is eliminated without crystallization. In a paper at page 1411 of the B.M.F. this week Dr. J. C. Crawhall, Professor E. F. Scowen, and Dr. R. W. E. Watts describe their experience with it in the treatment of seven patients with cystinuria. Though further calculi do not appear to have formed, three patients had cutaneous reactions, one severe enough to warrant cessation of treatment. Since the disease may damage the kidneys it is important to diagnose it before the harm is irreversible. Consequently it is worth considering in the differential diagnosis of many cases of renal stone.

\footnotetext{
1 Crawhall, J. C., Scowen, E. F., and Watts, R. W. E., Brit. med. f., $1963,1,588$.

2 Ibid., 1963, 1, 1496.

${ }_{3}$ Chalmers, J. N. M., and Whitehead, T. P., Recent Advances in Clinical Pathology (Series 4), 1964. Churchill, London.

4 Adams, D. A., Goldman, R., Maxwell, M. H., and Latta, A., Amer. f. Med., 1964, 36, 330 .
} 
In the treatment of cystinuria the patient should take copious fluids to keep the output of urine high, and keeping the urine alkaline has been recommended to increase the solubility of the cystine. The use of D-penicillamine in large dosage is still in the experimental stage and should not be lightly undertaken. It requires careful control, and it may cause allergic and nephrotoxic reactions. ${ }^{4}$

\section{Chemical and Biological Warfare}

The realization that chemistry might be an important weapon in modern warfare dates from the first gas attack at Ypres in 1915. A year later the Chemical Defence Experimental Establishment was set up at Porton near Salisbury. It has continued there ever since, moving at intervals from the control of one Government department to another and ending recently under the Ministry of Defence. It was joined after the second World War by an establishment dealing with defence against another brand of scientific warfare, the Microbiological Research Establishment. These two establishments were opened to the Press on 25 May; this was the first such visit to be allowed at the chemical research laboratories. The emphasis throughout was that Porton is not, as it has been sometimes represented, a sinister secret place where unmentionable new weapons are hatched and tested, but a complex of laboratories directed essentially towards protection against dangers which research workers there hope firmly will never occur.

Work in the bacteriological section inevitably has considerable bearing on ordinary medical research and overlaps with it at almost every point. Many of the experimental developments shown have peaceable applications. One example of this is the rapid identification of viruses by fluorescin-dye techniques. Another is the effort to develop the continuous culture of organisms as a substitute for the more usual batch method. This may have useful implications in the bulk production of antibiotics, vaccines, and amino-acids such as glutamic acid which may be used in foodstuffs. In another laboratory the invasive properties of bacteria are receiving attention, particularly in relation to the substance "aggressin" that assists invasion of tissues. Techniques have been developed for studying organisms isolated directly from infected animals, since there is evidence that they may have important chemical differences from those grown in laboratory media. In studies on brucella the growth-stimulant erythritol, which leads to the localization of the disease in the placenta of animals, is being investigated in the hope that modifications of its structure may produce a chemotherapeutic agent. Work on invasiveness of tumours has also recently been initiated in collaboration with the British Empire Cancer Campaign and the Chester Beatty Research Institute.

The Chemical Defence Establishment is concerned largely with gases, and these fall into two groups, the lethal poisons and the incapacitating agents. The lethal poisons have their ancestry in the gases developed in the first World War, but they acquired an additional importance when the Germans discovered the so-called "nerve gases" in 1939. These are organophosphorus compounds, closely related to some insecticides in common use to-day. They act by the inhibition of cholinesterase and are still, so far as is known, the most lethal substances which could be effectively used for the purposes of warfare. Since a fatal dose may be assimilated in a few seconds, the problem of early detection is fundamental, and research has been directed towards developing a compact and portable kit. An effective detection apparatus was demonstrated which was little larger than a small portable radio. Improved gas-masks and a disposable protective suit of clothing were also shown. Treatment of poisoning is by the injection as quickly as possible of atropine and another substance known as P2S. A new powder treatment has also been developed which effectively removes dangerous liquid from the skin.

Despite the essentially defensive nature of these establishments, it is unreal to imagine that the possibilities of the offensive are never taken into consideration. As one of the speakers pointed out, it is sometimes necessary to make research quantities of a gas so as to find out if it can be synthesized, since it is on this that its quality as a threat depends. It is an unhappy state of affairs that so much valuable scientific effort should be directed towards dangers that need never come if man retains some remnant of sanity. Perhaps we shall live to see the day when these laboratories will be turned over to wholly peaceful uses. If that day comes, no one will be more pleased than the Porton scientists themselves.

\section{Accidents in the Home}

During the last ten years in Great Britain there have been 80,000 deaths from accidents in the home, including nearly 10,000 of children under 15 and mainly very young children. Our knowledge of the size of the problem is limited because home accidents are not notifiable, but their incidence must be large. A report published this week by the B.M.A. ${ }^{1}$ is particularly valuable because it is based on surveys of nonfatal domestic accidents in seven different types of area with a total population of more than half a million people. A disappointing feature of these surveys, which lasted a year, was the limited response of the general practitioners, for less than half agreed to participate. In contrast the two-year survey in Denmark recently organized and directed by $\mathrm{E}$. Pedersen $^{2}$ was said to have covered every home accident in an urban and rural area of 100,000 population. The public has always been less concerned about home accidents than about those occurring on the roads, but home accidents can be seen to provide a large and continuing burden for the doctor if, as the report estimates, the number of injured people requiring medical attention is at least 15,000 a week and 70,000 receive hospital in-patient treatment every year.

The report confirms that children are particularly vulnerable, especially between the ages of 1 and 3 years. Surely many of these accidents ought to be prevented. The high incidence of burns and scalds with their dreadful sequelae, and the amount of accidental poisoning, especially in young children, is a reflection on the casual attention which

1 Accidents in the Home. British Medical Association. 4s., 1964.

2 Pedersen, E., Ugeskr. Lag., 1964, 126, 130.

3 Brit. med. f., 1964, 1, 652.

4 Sheldon, J. H., ibid., 1960, 2, 1685.

5 Ibid., 1964, 1, 255. 